\title{
ART WORKS Projects: \\ Claiming Public Space for Human Rights
}

Leslie Thomas, Founder of ART WORKS Projects

ART WORKS Projects (AWP) was born out of desperation. A photo of a small boy who had been murdered in a genocidal attack against civilians in Darfur by a Sudanese government intent upon their eradication led to the formation, first, of the DARFUR/DARFUR exhibition of large-scale exterior projections and, eventually, to AWP. The founders, by and large architects, filmmakers, editors, photographers, lawyers, and designers, weren't naive enough to believe that art can always end genocide (or any other grave human rights abuse), but they knew it impacted them and so they theorized that the same could happen to policymakers, voters, and, ultimately, perpetrators.

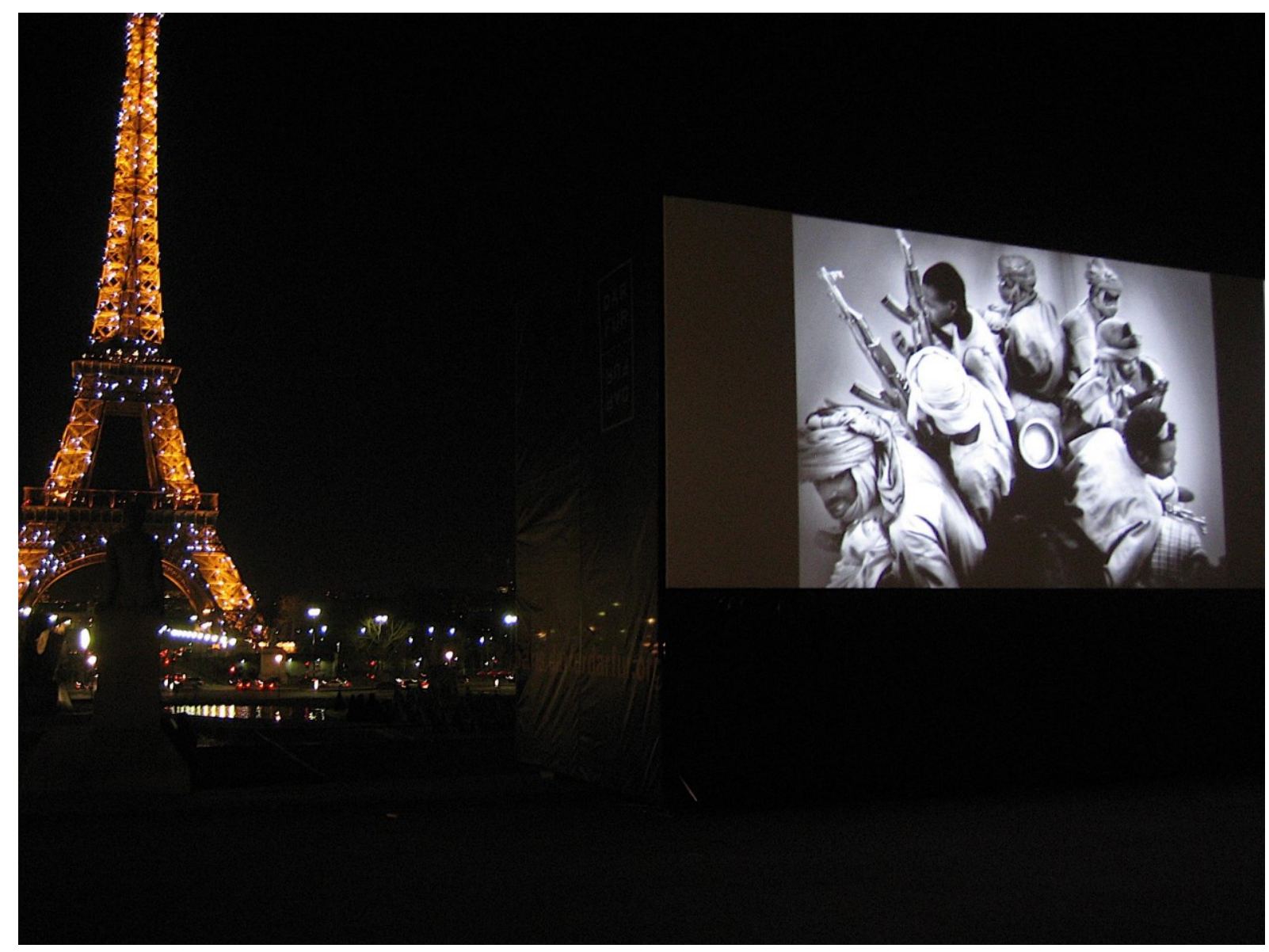

DARFUR/DARFUR projection in Paris in 2008. 


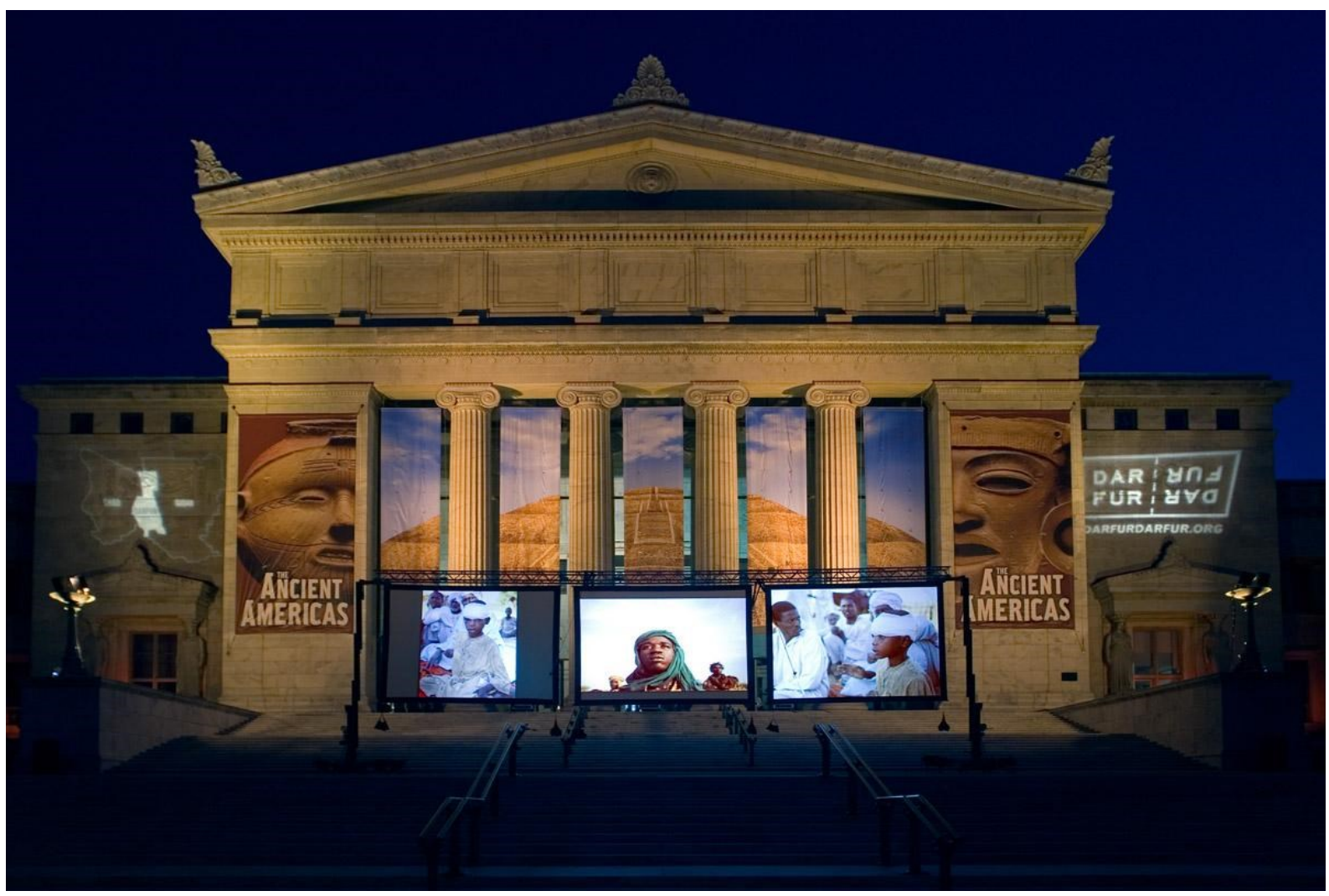

DARFUR/DARFUR projection at the Field Museum in Chicago, Illinois in 2007.

\section{Building Connections}

The work was first created out of a desire to spark an emotional response - first, to assist individuals identify with human beings around the world impacted by genocide, human trafficking, sexual violence, and other grave rights abuses, and then, to act. In documenting the tragedy in Sudan and Chad, the exhibition was curated to illustrate the fact that victims of genocide are not simply "numbers" in a media report and to emphasize the fact that with each death we are losing a priceless member of humanity and that we all suffer collectively.

At the start, AWP targeted museums and cultural centers as hosts for the work, with the idea of reaching and motivating voters in major global political centers and "donor countries" to press elected officials to lean on Sudanese leader Omar al-Bashir (now convicted of war crimes) and his allies to end their violence. Through media attention, these installations in Washington DC, Los Angeles, New York, and Berlin quickly came to the attention of advocacy organizations with deep ties to policymakers at all levels, and more opportunities for impact were created. Founding Board Member and architect, Susan Rodriguez, pointed out that with these projections we were "claiming public space for human rights." Her words were more than accurate as images of the realities of conflict flickered across facades in Milan, Washington, D.C., Berlin, Los Angeles, Chicago and so many more cities, each time leaving a mark upon the hearts and minds of viewers.

Within a few months, it became clear that creating empathy is an essential first step, but that it was only truly effective if it was delivered with partners who had relationships with networks and communities who could make an impact on the specific abuse. AWP began to exhibit at European Union gatherings, present materials to divestment assessments for lawmakers, and deliver books and individual photos to the U.S. Senate Foreign Relations committee in support of hearings. 


\section{Reverse Engineering}

As the DARFUR/DARFUR project evolved and AWP added Congo/Women, AT WHAT COST_Human Trafficking/Forced Labor/Child Labor, BLOOD/STONES Burmese Rubies, and other initiatives, this became our methodology:

- Identify a grave human rights abuse that was not being addressed

- Gather input from directly impacted stakeholders, global civil society members, policy makers, and others to see what solutions were being proposed and what the obstacles might be

- Decide where public art initiatives could reach the target audiences and move the needle

If the above criteria could be met, then we would design an initiative. Of course, the first criterion is an unsolvable riddle. What grave human rights abuse doesn't need more attention? As long as rights are being abrogated, we all must act. But over time, AWP began to realize that as a very small organization with a specific methodology, we could and should focus on a specific type of challenge: the gravest rights abuses (to paraphrase one of our long-term civil society colleagues, Jobi Cates, Founder of Restore Justice Illinois, this work is like swimming in the deep end of the pool). Additionally, we had to be extremely clear on whether the issue could be impacted by art. Some challenges are solved by diplomacy in private, not through civil society action and in that case, we pass. Others are solved with pressure from a vibrant and active and informed society (most, we would argue), and that is where AWP is most suited to be effective. This is part of philosopher Karl Popper's theory of an open society - and it is ours, as well.

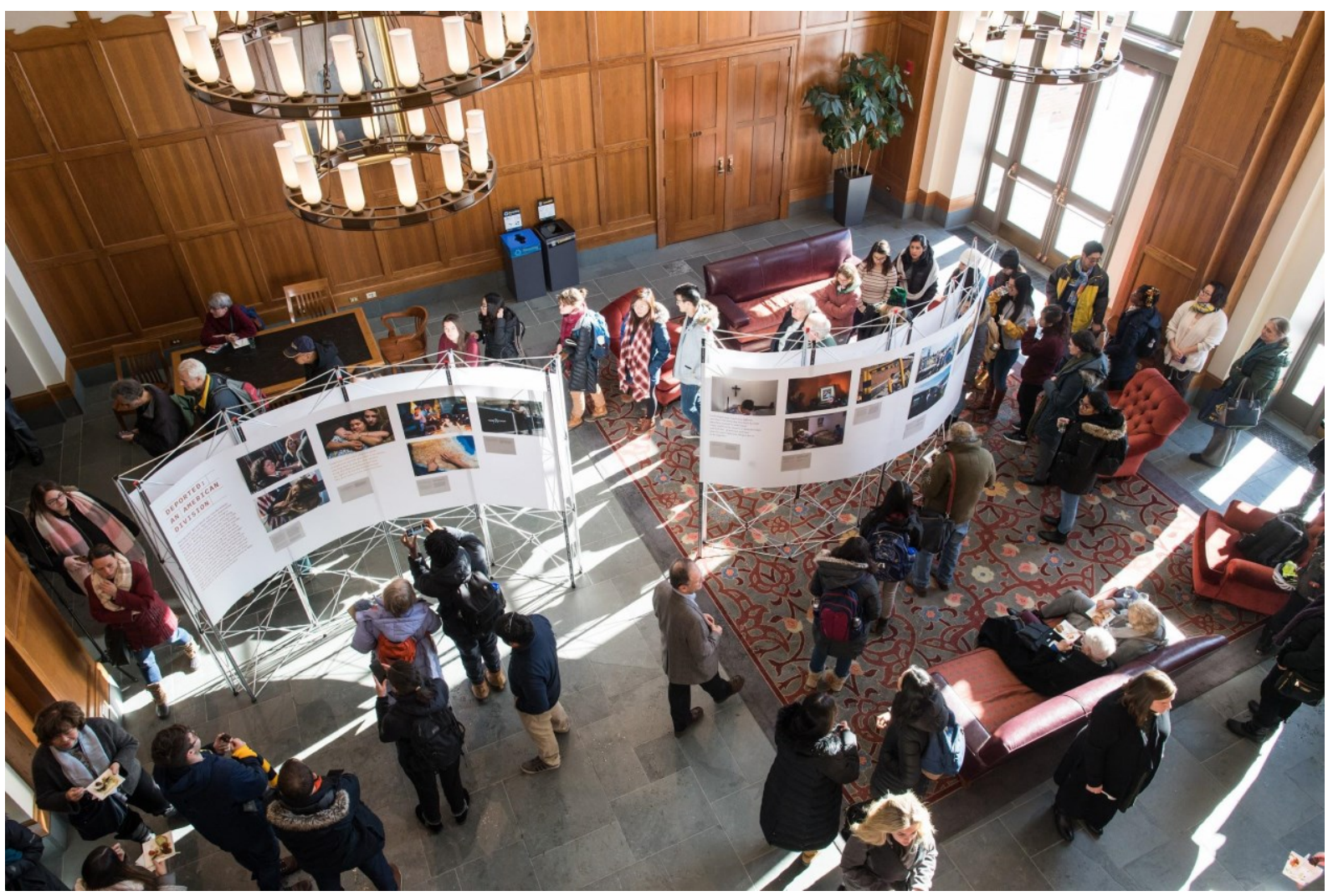

Deported: An American Division installation at the University of Michigan in Ann Arbor, Michigan. Image courtesy of the Gerald Ford School of Public Policy, University of Michigan. 
Having written that, as AWP evolved, we realized that in some ways our most effective work was the "direct to policymaker" effort. Fairly soon after we began, we noticed that the multimedia exhibition format could be adjusted to events in the European Union, at the African Union Summit, in the United States Congress, and so forth. As a result, we began to find that sometimes it isn't about reaching a large audience - it's about reaching the four senior members of the United States Senate Foreign Relations Committee by standing in front of 16x20' images of children trying desperately to survive bombing in Eastern Ghouta, Syria, and discussing it with the committee chair, or by bringing the stories of Haitian workers forced into labor to the global organization charged with ending this crime.

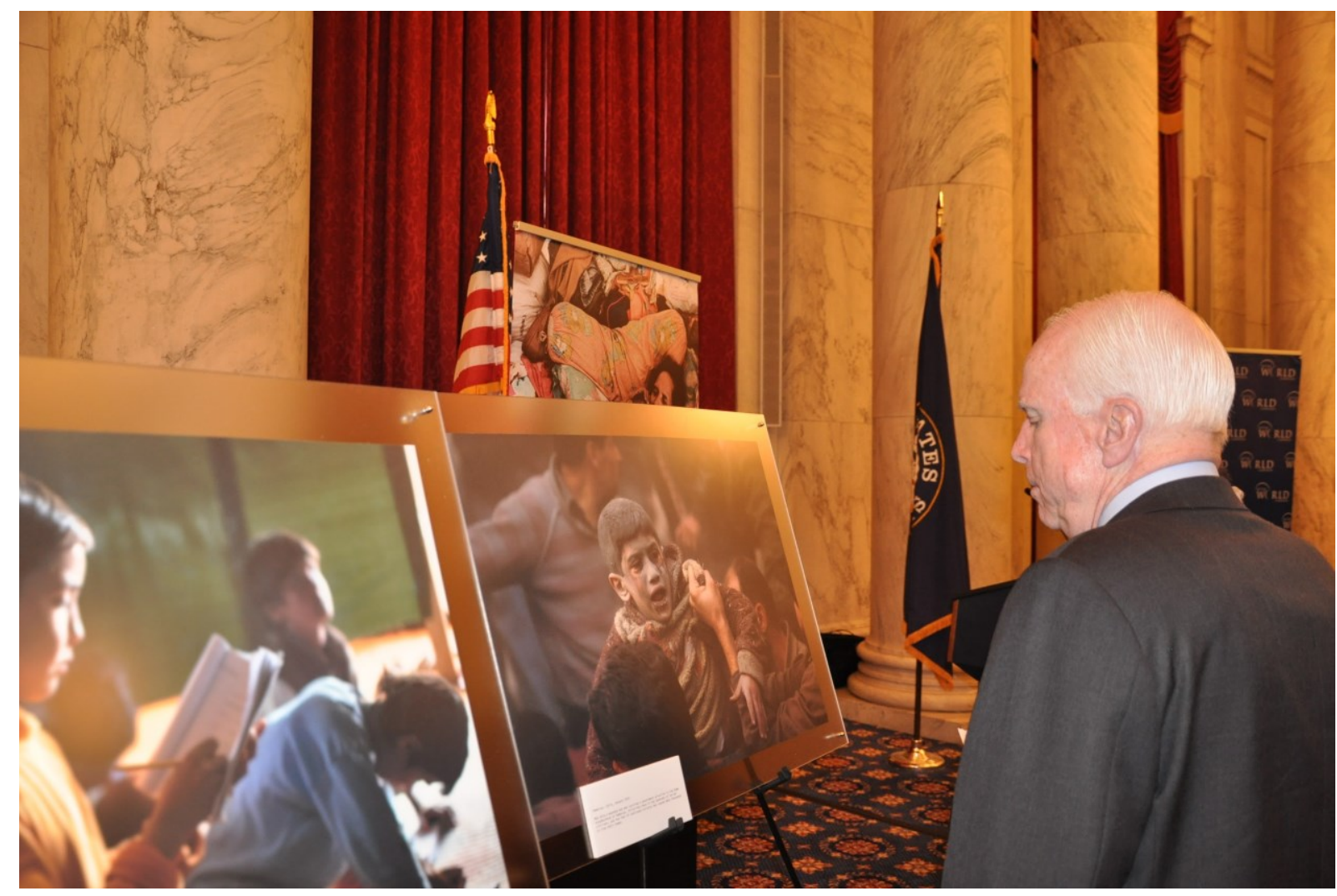

Senator John McCain viewing Children of Syria on Capitol Hill in Washington, D.C.

Over the years we've created photo exhibitions printed on fabric and paper, we've produced digital installations 30' high and 60' long, we have recently completed our first feature-length documentary film, and we've got so many more initiatives to tackle.

Perhaps, most importantly, we've been working hard to ensure that those most directly impacted are steering the conversation, that leadership needs to come from the best human rights experts - those who have been impacted and their allies.

We are always learning how to claim public space - whether that be the world wide web or a gallery - for human rights. 